\title{
PERLINDUNGAN HAK KEKAYAAN INTELEKTUAL TERHADAP PERBATIKAN (TINJAUAN TERHADAP BATIK YOGYAKARTA DAN SOLO)
}

\author{
Euis Sunaryo \\ Program Studi Magister Ilmu Hukum Universitas Al Azhar Indonesia
}

Contact: euis.sunaryo@yahoo.com

Diterima: 14 Sep 2018

Direvisi: 10 Nov 2018

Disetujui:12 Des 2018

Hak Cipta: (C2019

Halaman: 12-21

\begin{abstract}
One of the traditional knowledges in the arts and culture that is protected by Indonesia is Batik. Traditional batik with its classic motifs has been worked on for generations and is included in Traditional Knowledge and Traditional Cultural Expressions. Not all batik is registered for copyright because batik that needs copyright protection under Article 11 paragraph (1) letter $\mathrm{f}$ of the 1987 Copyright Act is a new art of batik. The problem that arises is how the legal protection of Yogyakarta Batik and Solo Batik is applied as Traditional Knowledge and Intellectual Property Rights (IPR). The purpose of this research is to know and understand the legal protection that can be obtained by Batik Yogyakarta and Batik Solo as the application of Traditional Knowledge and Intellectual Property Rights (IPR). The main theory used in this thesis research is John Locke's theory of Natural Law which states that the concept of property has something to do with human rights with its statement 'life, liberty, property'. The research method used is empirical normative research with qualitative research carried out in the field (field research) and take a research method with a non-judicial case study approach. The conclusion of the research is legal protection for Batik Yogyakarta and Solo as Traditional Knowledge carried out by the State by inventorying traditional batik motifs and maintaining Traditional Knowledge and Traditional Cultural Expressions.

The legal protection of Intellectual Property Rights (IPR) that can be applied to Yogyakarta and Solo Batik is through the Copyright, Trademark, Patent and Trade Secret regimes.
\end{abstract}

Keywords: Batik, Traditional Knowledge, Intellectual Property Rights (IPR) 


\section{PENDAHULUAN}

Salah satu pengetahuan tradisional di bidang seni dan budaya yang dilindungi oleh Indonesia adalah Batik. Pengertian Batik adalah sehelai wastra (kain) yang digunakan dalam matra tradisional beragam hias pola tertentu dengan teknik pembuatan celup rintang menggunakan malam (lilin batik) sebagai perintang warna dan dibuat secara tradisional (Doellah, 2002: 10).

PTEBT (Pengetahuan Tradisional dan Ekspresi Budaya Tradisional/folklore) batik adalah mengenai motif-motif batik, cara pembuatannya dan juga penggunaan canting dalam pembuatan batik tradisional adalah ciri khas pada batik Indonesia sehingga menjadikannya berbeda dengan batik dari negara-negara lain. Pemerintah Indonesia secara jelas telah mengatur perlindungan folklore dalam Undang-undang Hak Cipta Nomor 19 Tahun 2002 yaitu pada Pasal 10 ayat (2) yang berbunyi "Negara memegang Hak Cipta atas folklore dan hasil kebudayaan rakyat yang menjadi milik bersama seperti hikayat, dongeng, legenda, lagu, kerajinan, koreografi, tarian, kaligrafi dan karya seni lainnya".

Sementara itu batik bermotif kontemporer (modern) adalah termasuk seni batik yang merupakan salah satu jenis ciptaan yang mendapat perlindungan hukum dalam Undang-undang Nomor 12 Tahun 1997 tentang Hak Cipta yang meliputi ciptaan dalam bidang ilmu pengetahuan, seni dan sastra. Salah satu bidang Hak Kekayaan Intelektual yang secara konseptual hanya melindungi ekspresi adalah hak cipta. Sementara penemuan teknologi di bidang pembatikan dapat memperoleh perlindungan HKI melalui pendaftaran paten.

Penelitian ini menjadi penting karena dua alasan, yaitu pertama, Batik Tradisional dengan motif klasiknya sudah dikerjakan secara turun temurun, diciptakan sejak zaman kerajaan dahulu dan termasuk dalam
Pengetahuan Tradisional dan Ekspresi Budaya Tradisional (PTEBT). Kedua, tidak semua batik didaftarkan hak ciptanya karena batik yang perlu dilindungi Hak Ciptanya berdasarkan Pasal 11 ayat (1) huruf f Undang-undang Hak Cipta Tahun 1987 adalah seni batik ciptaan baru.

Dari uraian diatas maka permasalahan yang dapat disusun antara lain:

1. Bagaimanakah perlindungan hukum yang bisa didapatkan oleh Batik Yogyakarta dan Batik Solo dalam penerapan Pengetahuan Tradisional?

2. Bagaimanakah perlindungan HKI yang didapatkan Batik Yogyakarta dan Batik Solo?

\section{METODE PENELITIAN}

Metode yang digunakan adalah penelitian hukum normatif empiris. Penelitian normatif menganalisis norma hukum, yaitu hukum dalam arti perundang-undangan (Soekanto dan Mamudji, 1985: 14). Sementara penelitian hukum empiris menganalisis hukum dari perspektif eksternal dengan obyek penelitiannya adalah sikap, perilaku sosial dan kenyataan kultur terhadap hukum (Diantha, 2016: 12). Pendekatan dalam penelitian ini bersifat kualitatif yang dilaksanakan di lapangan (field research). Penggunaan pendekatan tersebut dalam penelitian ini setidaknya karena dua alasan yaitu, pertama, penelitian dilakukan mengacu kepada norma-norma hukum yang terdapat dalam peraturan perundang-undangan yang terkait dengan hierarki perundang-undangan hukum hak cipta, hukum paten dan hukum merek. Kedua, penelitian ini mengemukakan permasalahan hukum terkait pengaturan hak cipta motif batik tradisional dan motif batik kontemporer.

Sumber data penelitian terdiri atas data primer dan data sekunder. Data primer adalah data yang diperoleh langsung dari obyeknya, dalam hal ini adalah para pembatik di wilayah Provinsi D.I Yogyakarta 
dan Kotamadya Surakarta, Konsultan HKI dari Universitas Islam Indonesia, pejabat berwenang di lingkungan Dinas Perindustrian dan Perdagangan serta pejabat berwenang di lingkup Balai Besar Kerajinan dan Batik Yogyakarta. Data sekunder terdiri atas bahan hukum primer dan bahan hukum sekunder. Metode analisis data yang digunakan adalah menggunakan cara deskriptif kualitatif.

\section{KERANGKA TEORI}

Teori yang digunakan dalam penelitian ini adalah teori dari Robert C. Sherwood mengenai reward theory dan incentive theory serta teori Hukum Alam (natural right). Reward theory memiliki makna mendalam terhadap pengakuan karya intelektual yang dihasilkan oleh penemu, pencipta atau pendesain sehingga ia harus diberi penghargaan sebagai imbalan atas upaya kreatifnya (Sudaryat dan Permata, 2010: 1920). Justifikasi terhadap beberapa konsep perlindungan didasarkan pada incentive theory, yakni agar suatu karya cipta bisa berkembang maka sang pencipta diberikan suatu insentif baik penghargaan secara ekonomi dan moral atas hasil ciptaannya (Keringer, 1996: 14). Teori Hukum Alam digunakan sebagai landasan moral dan filosofis atas tuntutan untuk melindungi kekayaan intelektual dan sangat berpengaruh terhadap individu yang menciptakan pelbagai ciptaan yang memperoleh perlindungan hukum atas karya intelektualnya (Yusuf, 1994: 170). Menurut John Locke hukum hak cipta memberikan hak eksklusif kepada karya cipta dari seorang pencipta. Hukum Alam meminta individu untuk menguasai karya-karyanya dan secara adil dikompensasikan untuk didistribusikan kepada masyarakat (Purba dan Saleh, 2005: 3).

\section{HASIL DAN PEMBAHASAN}

\section{Perlindungan Hukum Terhadap Batik Yogyakarta dan Batik Solo dalam Penerapan sebagai Pengetahuan Tradisional}

\section{Perkembangan Seni Batik Indonesia}

Batik secara umum adalah teknik menghias permukaan kain (tekstil) dengan cara menahan warna menggunakan malam (wax). Sebenarnya proses membatik ini ada di beragam peradaban termasuk di benua Afrika, Asia, Amerika dan Eropa.

Batik Indonesia memiliki karakter khusus yang membedakannya dengan batik dari negara-negara lain, yaitu batik Indonesia berkembang dan merupakan bagian dari kesenian keraton Jawa, batik harus menggunakan canting dengan metode waxing dan batik memiliki pakem. Ciri khas batik tradisional Indonesia menurut Iwan Tirta adalah berhubungan erat dengan bidangbidang kebudayaan Jawa yang lain, bersifat universal yang artinya lintas sara dan agama serta teknik yang pasti yaitu penahan warna (Tirta, 2009: 223).

Motif batik yang biasa disebut sebagai corak batik diartikan sebagai kerangka gambar yang mewujudkan batik secara keseluruhan. Ragam hias motif batik mengungkapkan adanya latar belakang kebudayaan, kepercayaan, adat-istiadat, sifat dan tata kehidupan, alam lingkungan, cita rasa dan tingkat keterampilannya (Istari, 2012: 69). Ragam hias adalah hasil kebudayaan yang berkesinambungan dengan local genius (cultural identity), yaitu kemampuan menyerap dan mengolah pengaruh kebudayaan sehingga dapat mencapai suatu ciptaan baru yang tidak ada pada wilayah bangsa yang membawa pengaruh budaya tersebut. (Soebadjo, 1985: 21-23). Bangsa Indonesia sudah memiliki kemampuan itu sejak dahulu, jika unsur-unsur budaya luar dianggap cocok dengan pola kebudayaan yang sudah ada maka transformasi antara 
dua budaya tersebut diberi identitas lokal atau menciptakan sendiri sesuatu yng dianggap hasil karya budayanya.

Selain motif-motif dan teknik pembuatannya, terdapat hal penting lain dari proses membatik secara tradisional, yaitu perlengkapan membuat batik dengan menggunakan canting. Canting sebagai alat membatik adalah penemuan kreatif orang Jawa yang tiada duanya di dunia yang menerapkan salah satu teknik membatik. Kemungkinannya canting adalah hasil pengembangan di lingkungan keraton Mataram pada abad ke-17. (Veldhuisen, 1983: 31 terjemahan Setiadi, 2007: 22)

Pendapat yang menyatakan bahwa asal mula batik Jawa terpengaruh kebudayaan India dan dibawa oleh orang Kalinga Koromandel adalah kurang tepat, alasannya (Susanto, 1974: 294-295).

a. Jika seni batik langsung dipengaruhi Kalinga, mengapa di India tidak terdapat motif-motif Kawung, Lereng, Ceplok dan Cinden dimana semua motif tersebut muncul di Indonesia antara abad ke-9 sampai dengan abad ke-14.

b. Proses 'wax resist technique' tidak hanya terdapat di India saja. Pengaruh hubungan Indonesia-Tiongkok pada zaman Sriwijaya yang erat sekali lebih memungkinkan adanya hubungan timbal balik.

c. Perkembangan batik secara wax resist pada batik Indonesia mencapai kesempurnaan antara abad ke-14 sampai dengan abad ke-15, sedangkan di India baru tercapai pada abad ke-17 sampai ke-19.

d. Beberapa daerah di Indonesia yang tidak kena pengaruh Hindu seperti Toraja Sulawesi, dahulu pernah berkembang batik yang dibuat secara wax resist dyeing.

Pada mulanya candi-candi di Indonesia dianalogikan dengan candi-candi di India yang berfungsi sebagai tempat pemujaan. Belakangan diketahui fungsi candi di Indonesia adalah sebagai tempat penyimpanan abu jenazah atau sebagai makam. Melalui seni arca khususnya pakaian yang digambarkan pada patung-patung dapat terlihat perkembangan seni batik seperti yang terdapat pada patung Siwa yang menggunakan dasar motif Lereng pada pakaiannya (Candi Dieng abad ke-9) atau motif Ceplok yang terlihat pada pakaian patung Ganesha yang terdapat di Candi Banon komplek Candi Borobudur (abad ke9).

\section{Pengetahuan Tradisional Batik dan Hak Kekayaan Intelektual}

Pengertian batik sebagai Pengetahuan Tradisional dalam Rancangan Undangundang Pengetahuan Tradisional dan Ekspresi Budaya Tradisional (RUU PTEBT) adalah apabila mengandung dua unsur pokok yaitu teknik celup rintang menggunakan lilin sebagai perintang warna dan pola yang beragam hias khas batik. Pengetahuan Tradisional batik adalah mengenai cara pembuatan batik dan juga penggunaan canting dalam pembuatan batik tradisional sebagai ciri khas batik Indonesia. Ekspresi Budaya Tradisional batik adalah pada motifmotif batiknya. Sejarah perlindungan folklore di Indonesia melalui perundang-undangan adalah Undang-undang Hak Cipta 1982, UU Hak Cipta Nomor 19 Tahun 2002 Tentang Hak Cipta dan Pasal 13 RUU Hak Cipta Tahun 2010.

Pengetahuan Tradisional dan Ekspresi Budaya Tradisional (PTEBT) ketika berhadapan dengan HKI menghadapi sejumlah dilema seperti:

a). Pihak yang ingin melakukan perlindungan PTEBT ke dalam rezim HKI. Perlindungan HKI bersifat personal sementara Pengetahuan Tradisional dimiliki secara komunal, tidak diketahui siapa penciptanya (anonim) dan ekspresi kultural tidak dimonopoli oleh suatu kelompok tertentu.

b). Pihak yang ingin membebaskan belenggu HKI kepada kebudayaan tradisional. Perlindungan kebudayaan tradisional dalam bentuk kepemilikan apakah perkembangan yang sehat atau justru membekukan 
kebudayaan tradisional itu sendiri. Padahal hidup di era global saling meminjam unsur kebudayaan adalah tak terelakkan (Haryanto, 2004). Bahkan sebenarnya sejak jaman dahulupun tidak ada yang betul-betul asli.

c). Pengetahuan Tradisional adalah kreasi yang umumnya telah terpublikasi. Salah satu syarat dalam rezim HKI (seperti paten dan desain industri) mengharuskan adanya kebaruan (novelty).

d). Hak Cipta mempersyaratkan bentuk formal (fixation). Folklore tidak dalam bentuk tertentu, biasanya diekspresikan secara lisan dan diwariskan antar generasi dalam masyarakat yang bersangkutan.

\section{Perlindungan Hukum Batik Bagi Pengetahuan Tradisional}

Perlindungan pengetahuan tradisional dilatar belakangi adanya misappropriation yaitu penggunaan pengetahuan tradisional milik suatu masyarakat, tetapi dimanfaatkan oleh pihak asing dengan mengabaikan hak-hak masyarakat lokal sebagai pemiliknya (Sardjono, 2010: 11).

Bentuk-bentuk perlindungan hukum bagi pengetahuan tradisional batik dapat dilakukan melalui dua cara yaitu (Ayu, dkk, 2014: 111-137)

a) Perlindungan Positif, dengan cara pembentukan hukum dan tindakan hukum negara.

b) Perlindungan Defensif, dilakukan dengan cara pendokumentasian Pengetahuan Tradisional dan melindungi pengetahuan tersebut sebagai aset kekayaan intelektual. Perlindungan hukum terhadap pengetahuan tradisional dapat dilakukan dengan dua cara, yaitu melalui perlindungan jangka pendek, menengah, dan panjang. Perlindungan jangka pendek melalui sistem inventarisasi dokumen pengetahuan tradisional, hal ini selain sebagai fungsi normatif juga sebagai sarana untuk fungsi pembuktian hukum. Adapun perlindungan jangka menengah dan panjang, pemerintah mengeluarkan undangundang yang secara khusus melindungi pengetahuan tradisional.
Peluang untuk memberikan perlindungan hukum di tingkat internasional terhadap Pengetahuan Tradisional dan Ekspresi Budaya Tradisional menjadi semakin besar karena sejumlah faktor, antara lain:

\section{1). Pasal 12 paragraf viii Agreement Establishing the World Intellectual Property Organization, bahwa yang} dimaksud Kekayaan Intelektual termasuk didalamnya yang menurut beberapa pihak frasa tersebut mengandung arti bahwa karya-karya yang dihasilkan melalui pemikiran di luar yang sudah saat ini tetap diberikan ruang.

\section{2). Pasal 8 paragraf $j$ Convention on} Biological Diversity 1992, yang mewajibkan negara anggotanya untuk menghormati, memelihara dan melestarikan pengetahuan, inovasi dan praktik masyarakat adat dan lokal yang mewujudkan gaya hidup tradisional yang relevan untuk konservasi dan mempromosikan aplikasi yang lebih luas dengan persetujuan dan keterlibatan para pemegang pengetahuan tersebut.

1) WTO Report on Fact-Finding Missions on Intellectual Property and Traditional Knowledge (1998-1999)

2) Pembentukan IGC GRTKF

(Intergovernmental Committee on Intellectual Property and Genetic Resouces, Traditional Knowledge and Folklore) oleh WIPO

3) Like Minded Countries (LMCs) meetings (2009-sekarang), diinisiasi oleh Indonesia dan Afrika Selatan dengan tujuan mengupayakan dibentuknya perlindungan hukum terhadap PTEBT di negara-negara yang memiliki pandangan sama terhadap isu.

Terdapat beberapa sumber hukum internasional yang hingga saat ini dijadikan sumber hukum untuk mengakomodasi perlindungan pengetahuan tradisional antara lain Nagoya Protocol on Access to Genetic Resources and The Fair and Equitable Sharing on Benefits tahun 2010, Cartagena Protocol 
on Biosafety tahun 2000, United Nation Convention on Biological Diversity tahun 1992, Marrakech Agreement Establishing the World Trade Organization tahun 1995, International Covenant on Civil and Political Rights tahun 1966 dan International Covenant on Economic, Social and Cultural Rights tahun 1966. Selain sumber hukum formal terdapat pula soft law sebagai acuan terhadap perlindungan pengetahuan tradisional, seperti Universal Declaration of Human Rights tahun 1948 dan United Nations Declarations on Rights of Indigenous Peoples tahun 2007. Beberapa konvensi tersebut merupakan suatu bentuk perjanjian internasional yang mengikat bagi negaranegara anggotanya yang menerapkan perjanjian tersebut ke dalam negaranya (Kusumaatmaja, 1978: 11).

Rezim Hak Cipta adalah instrumen perlindungan bagi Pengetahuan Tradisional dan folklore/ Ekspresi Budaya Tradisional (EBT). Menurut Undang-undang Nomor 19 Tahun 2002 tentang Hak Cipta, budaya tradisional termasuk dalam karya ciptaan yang dilindungi seperti tercantum dalam Pasal 10 dan Pasal 12. Posisi negara dalam pasal 10 UU Hak Cipta adalah negara mewakili kepentingan rakyatnya dalam hal ini masyarakat tradisional di Indonesia sebagai pemegang hak cipta. Hal tersebut dilakukan apabila pihak asing memanfaatkan pengetahuan tradisionalnya dalam rangka sharing benefit (Sutedi, 2009: 181). Pada saaat sekarang ini Pengetahuan Tradisional dibagi menjadi dua, yaitu untuk yang berbasis Paten dinamakan Pengetahuan Tradisional sedangkan untuk yang berbasis Hak Cipta disebut folklore (Purwaningsih, 2012: 23-26). Syarat pengetahuan tradisional dapat dipatenkan adalah apabila memenuhi persyaratan patentable.

\section{Perlindungan HKI Bagi Batik Yogyakarta dan Batik Solo \\ Perjanjian Giyanti pada 13 Februari 1755 melahirkan Kasunanan Surakarta dan}

Kasultanan Yogyakarta, dimana segala macam tata adibusana termasuk batik diserahkan sepenuhnya kepada Keraton Yogyakarta. Ciri khas batik tradisional Kasultanan Yogyakarta adalah memiliki tampilan dasar putih mencolok bersih dan pola geometri khas bermotif besar. Sogan Yogyakarta didominasi warna coklat tua kehitaman dan putih. Adapun batik tradisional Kasunanan Surakarta memiliki tampilan dasar putih kecoklatan atau krem bermotif penuh. Warna sogan pada batik Surakarta berwarna coklat oranye dan coklat.

\section{Perlindungan HKI Bagi Batik Yogyakarta}

Salah satu pengrajin batik di daerah Yogyakarta yang menjadi sasaran penelitian adalah pengrajin batik yang berada di desa Trembono Gedangsari Kabupaten Gunung Kidul Yogyakarta. Para pengrajin dan seniman batik di Gedangsari biasanya menggunakan motif-motif tradisional khas Yogyakarta yang didominasi oleh gambar tumbuh-tumbuhan dan sebagian besar dibuat secara batik tulis. Narasumber yang penulis temui ini adalah pengrajin batik dengan merek Kalimosodo. Berlatar belakang seorang dalang mempengaruhi beliau dalam menciptakan sendiri motif-motifnya, yang selain didominasi oleh motif tumbuhan dan cerita pewayangan khasJawa. Hak Cipta atas batik motif cerita pewayangan ini sudah didaftarkan sejak 2012 tetapi hingga sekarang hak cipta atas karyanya tersebut belum beliau dapatkan (Surono, 2018).

Mengacu pada ketentuan Pasal 12 ayat (1) huruf I Undang-undang Nomor 19 Tahun 2002 Tentang Hak Cipta dengan berbagai peraturan pelaksanaannya, motif batik yang dapat didaftarkan adalah untuk desain motif batik yang baru dan bukan modifikasi motif lama. Perlindungan yang akan didapatkan atas karya motif cerita pewayangan tersebut, maka akan muncul hak eksklusif bagi pengrajin/pencipta untuk mempublikasikan/memperbanyak sendiri motif baru ciptaannya atau memberi ijin 
kepada pihak lain. Surat pendaftaran ciptaan dapat dijadikan sebagai alat bukti di pengadilan apabila timbul sengketa di kemudian hari atas motif batik tersebut. Bidang HKI yang dapat diterapkan pada Batik Kalimosodo selain merek adalah Hak Paten sederhana pada kain batiknya. Penggunaan zat pewarna alami menghasilkan tampilan warna yang khas pada Batik Kalimosodo. Sayangnya takaran-takaran yang dipergunakan pengrajin Batik Kalimosodo dalam mencampur pewarna alamnya masih menggunakan ukuran yang kurang terjamin tingkat akurasinya, sehingga belum dapat diterapkan dalam suatu proses industri sebagai syarat untuk mendapatkan hak patennya.

Menurut Budi Agus Riswandi, Konsultan HKI Universitas Islam Indonesia yang menjelaskan bahwa Batik Yogyakarta yang sudah memiliki hak cipta sesuai ketentuan Hak Cipta No. 19 Tahun 2002 contohnya antara lain motif batik Anggrek Tricolor dari Kabupaten Sleman dan motif batik Sekaring Gedangsari dari Kabupaten Bantul Yogyakarta yang mendapatkan surat pencatatan ciptaan dari Kementrian Hukum dan HAM Republik Indonesia (Riswandi,2018). Salah satu Hak Paten dalam bidang perbatikan adalah Hak Paten pembuatan Batik Obong. Teknik ini ditemukan oleh Lugiyantoro seorang warga Kabupaten Bantul Yogyakarta. Penelusuran dari Patent Public Domain Indonesia, Direktorat Jenderal Kekayaan Intelektual (DJKI) hanya mendapatkan tiga paten yang berkaitan dengan batik yaitu P00201000228; S00201000043; S00201000104 tentang pewarna batik, wajan batik listrik dan wajan kompor listrik.

Selain hasil karya para pengrajin batik Yogyakarta, invensi atas Hak Paten dan Hak Cipta motif batik juga ada yang diciptakan oleh pegawai Balai Besar Kerajinan dan Batik (BBKB). Pegawai BBKB dikarenakan posisinya sebagai pegawai negeri sipil (PNS) dan merupakan Aparatur Sipil Negara yang mempunyai hubungan dinas, kecuali diperjanjikan lain maka pemegang Hak Cipta yang dibuat oleh pencipta dalam hubungan dinas adalah instansi pemerintah tersebut. Hal ini diatur dalam Pasal 35 Undang-undang Nomor 28 Tahun 2014 Tentang Hak Cipta. Apabila di kemudian hari hasil ciptaan motif batiknya digunakan oleh para pengrajin dan industri batik untuk kegiatan komersial, maka pencipta motif batik tersebut yang juga pegawai dan instansinya dalam hal ini Balai Besar Kerajinan dan batik berhak untuk memperoleh royalti. Contoh invensi di bidang perbatikannya adalah ekstrasi rumput laut sebagai pewarna alam dari alga coklat (Sargassum filipendula dan Turbinaria) dan telah mendapatkan Hak Paten dengan No. Paten P00201200722, invensi komposisi lilin batik dengan paraffin wax substitute yang bertujuan untuk menyediakan lilin batik siap pakai jenis klowong tulis dan klowong cap dengan No. Paten P00201602170, serta invensi alat kompor batik berbahan gas yang menggunakan sistem otomatisasi elektronik untuk pengaturan suhu sesuai panas ideal yang dibutuhkan untuk melakukan pengecapan batik.

Menurut Maslahatul Hayah, Kabid Sub Bagian Kepegawaian Badan Penelitian dan Pengembangan Industri BBKB, posisi Balai Besar dan Kerajinan (BBKB) dapat dijadikan sebagai saksi ahli di bidang perbatikan bila terjadi sengketa hak cipta. Peranan BBKB sebagai saksi ahli khususnya pada motif batik, dilakukan melalui beberapa tahap untuk bisa menentukan apakah motif tersebut ada unsur kesamaan dimana hasilnya disampaikan secara lisan dan tertulis. (Hayah, 2018)

\section{Perlindungan HKI Bagi Batik Solo}

Kotamadya Surakarta juga dikenal sebagai sentra pengrajin batik terbaik di Indonesia dengan produknya yang dikenal sebagai Batik Solo. Langkah yang telah dilakukan Disperindag untuk pengembangan batik Solo 
menurut D. Puspandari seorang pejabat di lingkup Disperindag Kotamadya Surakarta adalah memfasilitasi pendaftaran merek terhadap produk-produk batik dan pendampingan kepada para pengrajin batik di lingkup Kotamadya Surakarta untuk mendapatkan sertifikasi Batikmark (Puspandari, 2018). Batik Solo baru memiliki lima Batikmark.

Pendaftaran Hak Cipta atas motif Batik Solo masih minim alasannya karena kurangnya kreatifitas untuk menghasilkan desain batik motif-motif yang baru, jika ada pengrajin yang memproduksi motif atau desain baru untuk produksinya ternyata sebagian besar motif batik yang terbaru tersebut adalah motif tradisional yang telah ditambahkan sedikit ornamen sehingga terlihat sebagai motif baru, serta tidak ada larangan untuk membuat motif batik yang mirip dengan produk sesama pengrajin batik lainnya. Sementara lamanya proses pendaftaran hak cipta yakni 1,5 tahun sehingga hak cipta atas motif batiknya belum keluar akan tetapi motif batik tersebut sudah di contoh dan diproduksi oleh pengrajin batik lainnya. Masalah hak cipta juga sulit diatasi karena adanya rasa tidak enak untuk menegur pengrajin batik lainnya dikarenakan banyak pengrajin atau pengusaha batik masih memiliki hubungan darah atau kekerabatan.

Hambatan lain yang dihadapi karya cipta Batik Solo dalam usaha pendaftaran hak ciptanya dikarenakan faktor-faktor berikut ini:

a) Substansi, yaitu masih banyaknya pencipta motif batik yang tidak mengetahui keberadaan Undang-undang Hak Cipta dan berlaku juga bagi para desainer batik di tingkat menengah ke bawah.

b) Struktur, yaitu layanan dari staf Direktorat Jendral HAKI masih bekerja dengan baik akan tetapi sistem pendaftarannya masih berbelit-belit dan biaya pendaftarannya masih mahal. c) Budaya, yaitu kebiasaan para pengrajin batik untuk melakukan penjiplakan atau peniruan motif adalah hal yang masih dianggap biasa.

Salah satu pengrajin batik di kota Solo yang menjadi sasaran penelitian adalah produk batik bermerek Mahkota Laweyan. Menurut Alpha Febela Priyatmono pemilik Batik Mahkota Laweyan dan Ketua Umum Pengembangan Kampung Batik Laweyan, produknya adalah batik tulis yang sudah memiliki 20 desain motif batik hasil karyanya sendiri akan tetapi baru 12 desain motif batiknya yang sudah memiliki Hak Cipta diantaranya motif Batik Arsitektur, Batik Sido Langgeng, Batik Super Maestro, Batik Persepsi, Batik Terakota, dan lain sebagainya. Menurut bapak Alpha adalah tidak masalah apabila motif batik ciptaannya yang telah didaftarkan hak ciptanya ditiru atau digunakan oleh para pengrajin batik lainnya (Priyatmono, 20 April 2018). Hal ini dikarenakan menurut beliau manusia hanyalah sebagai alat sedangkan ilham didapat dari Tuhan YME dan digunakan sebagai alat untuk berdakwah, kecuali bila motif batik ciptaannya digunakan oleh seniman atau pengrajin batik dari mancanegara barulah beliau akan memprotes karena dinilai merugikan negara dan bangsa Indonesia.

Forum Pengembangan Kampung Batik Laweyan Surakarta adalah suatu komunitas pengrajin batik di Laweyan dimana komunitas tersebut sudah memiliki label Batikmark untuk produk batiknya dan merek kolektif Batik Laweyan. Merek kolektif menurut Pasal 1 ayat (4) Undang-undang Republik Indonesia Nomor 19 Tentang Merek adalah merek yang digunakan pada barang atau jasa dengan karakteristik yang sama yang diperdagangkan oleh beberapa orang atau badan hukum secara bersamasama untuk membedakan dengan barang atau jasa sejenis lainnya. Adapun proses motifnya adalah komunal Laweyan. 
Para pengrajin batik di sentra-sentra industri batik mempunyai metode atau cara tersendiri untuk memenangkan persaingan di usaha perbatikan. Menurut penelitian yang dilakukan oleh Selvie Sinaga, sebagian pengrajin batik tidak mengkhawatirkan apabila orang lain mengetahui rahasia dagang mereka. Terdapat pengaplikasian metode yang berbeda untuk melindungi asset intelektual propertinya, antara lain (Sinaga, 2012: 282):

a) Pengrajin skala menengah (medium enterprise) dengan produk Batik Tulis 85\% dan Batik Cap 15\%, melindungi Rahasia Dagangnya dengan tidak membiarkan karyawannya terutama yang masih baru dan tidak dipercayai untuk mengetahui seluruh proses pewarnaan batik.

b) Pengrajin batik skala menengah dengan produk Batik Printing dan Cap, melindungi Rahasia Dagang dengan hanya membuka sebagian informasi dari keseluruhan proses produksinya kepada karyawan sehingga tidak ada yang memahami prosesnya dari awal hingga akhir.

c) Pengrajin batik skala menengah (medium) dengan produknya batik printing dan tekstil untuk peralatan rumah tangga (household fabric) seperti taplak meja, bedcover, sprei dan lain-lain, hanya mengijinkan anggota keluarga saja untuk bekerja dan mengatur hal-hal yang diputuskan sebagai Rahasia Dagang bisnisnya.

Perlindungan Batik Yogyakarta dan Solo sebagai Pengetahuan Tradisional dan motifmotif batik tradisionalnya sebagai Ekspresi Budaya Tradisional, serta batik kontemporernya yang dimiliki individu sebagai HKI adalah sesuai dengan teori hak kekayaan intelektual reward theory dimana pencipta atau penemu diberi penghargaan atas hasil jerih payahnya dalam menghasilkan ciptaan atau penemuan. Pengakuan dan perlindungan Hak Cipta motif-motif batik kontemporer adalah dalam rangka menarik pengembangan kreativitas penemuan. Perlindungannnya menurut incentive theory adalah dengan memberikan suatu insentif agar kegiatan penelitian dan penciptaan dapat terjadi lagi, sehingga Pengetahuan Tradisional dan Hak Kekayaan Intelektual Batik Yogyakarta dan Batik Solo akan tetap lestari.

\section{KESIMPULAN}

1. Perlindungan hukum terhadap Batik Yogyakarta dan Batik Solo dalam penerapannya sebagai pengetahuan Tradisional dan Ekspresi Budaya Tradisional dilakukan secara Positif dan Defensif. Perlindungan Positif melalui Hukum HKI dan Hukum Kontrak, sementara secara defensif dilakukan melalui usaha untuk menginventarisasi motif-motif tradisional batik baik motif tradisional Yogyakarta dan Solo.

2. Perlindungan hukum HKI yang dapat diterapkan pada Batik Yogyakarta adalah melalui rezim Hak Cipta, Merek dan Paten.

3. Perlindungan hukum HKI yang diterapkan pada Batik Solo adalah melalui rezim Hak Cipta, Merek dan Rahasia Dagang.

\section{DAFTAR PUSTAKA}

Amirudin dan Asikin, Zainal. 2006. Pengantar Metode Penelitian Hukum. Jakarta. PT. Raja Grafindo Persada

Ayu, Miranda Risang, dkk. 2014. Hukum Sumber Daya Genetik, Pengetahuan Tradisional dan Ekspresi Budaya Tradisional. Bandung. PT. Alumni.

Diantha, I Made Pasek. 2016. Metodologi Hukum Normatif. Jakarta. Prenada Media Grup.

Doellah, Santosa. 2002. Batik Pengaruh Zaman dan Lingkungan. Solo. PT. Batik Danar Hadi.

Harian Kompas Edisi (2004, Oct 10). 
Keringer, Pred N., 1996. Asas-asas Penelitian Behaviora Edisi Indonesia Cetakan ke-5. Yogyakarta. Gadjah Mada University Press.

Kusumaatmaja, Mochtar. 1978. Pengantar Hukum Internasional. Jakarta. Bina Cipta.

Marzuki, Peter Mahmud. 2005. Penelitian Hukum. Jakarta. Kencana Prenada Media Grup.

Purba, Afrillyana dan Saleh, Gazalba. 2005. TRIPs-WTO dan Hukum HKI Indonesia. Jakarta. Rineka Cipta.

Purwaningsih, Endang. 2012. HKI dan Lisensi. Bandung. CV. Mandar Maju.

Saleh, Ismail. 1990. Hukum dan Ekonomi. Jakarta. Gramedia Pustaka Utama.

Sardjono, Agus. 2010. HKI dan Pengetahuan Tradisional. Bandung. PT. Alumni.

Soebadio, Haryati. 1985. Kepribadian Budaya Bangsa (local genius). Jakarta. Pustaka Jaya.

Soekanto, Soerjono dan Mamudji, Sri. 1985. Penelitian Hukum Normatif. Jakarta. Radjawali.

Sudaryat, Sudjana dan Permata, Rika Ratna. 2010. Hak Kekayaan Intelektual: Memahami Prinsip Dasar, Cakupan dan Undang-undang yang Berlaku. Bandung. Oase Media.

Susanto, S.K Sewan. 1974. Seni Kerajinan Batik Indonesia. Yogyakarta. Balai Penelitian Batik dan Kerajinan.

Sutedi, Adrian. 2009. Hak Atas Kekayaan Intelektual. Jakarta. Sinar Grafika.

Sinaga, Selvie. 2012. "Utilisation of IPRs by Indonesian Small and Enterprises: A Case Study of Challenge Facing the Batik and Jamu Industries", Disertasi Faculty of Law University of Wollongong. Australia.
Tirta, Iwan. 2009. Batik Sebuah Lakon. Jakarta. PT. Gaya Favorit Press.

Veldhuisen, Harmen C., 1983." Ontwikkelingen in de Batik Van Java", 6 articles in Handweken Zon der Grenzen. Utrecht. Kluwerpers B.V. (edisi terjemahan oleh Setiadi, Agus. 2007. Batik Belanda 18401940: Pengaruh Belanda pada Batik dari Jawa. Sejarah dan Kisah-kisah di Sekitarnya Cetakan ke-1. Jakarta. Gaya Favorit Press).

Wahington Journal Law and Policy. 2000 (Vol. 2) No. 371.

Widya, Naditira. 2012 (Vol. 6) Nomor 1. Banjarmasin. Balai Arkeologi.

Yusuf, Asep Warlan. 1994. Masalah Hukum dan Kekuasaan dalam Perspektif Filsafat: Filsafat Hukum, Mazhab dan Refleksinya. Bandung. Remaja Rosdakarya. 